кации. - Текст : непосредственный // Мир культуры и культурология : альманах научно-образо-вательного культурологического общества России. - Санкт-Петербург : Изд-во РХГА, 2011. - С. 162-175.

Sargylana $V$. Nikiforova, Ph. D. in Cultural Studies, Associate Professor Ammosov North-Eastern Federal University (Yakutsk, Russia) nsv2107@mail.ru

Ekaterina A. Dyachkovskaya

Ammosov North-Eastern Federal University (Yakutsk, Russia) kachuuka@mail.ru

\title{
CULTURAL HERITAGE IN REGIONAL IDENTIFICATION STRATEGIES
}

\begin{abstract}
The article outlines a role that objects of cultural and natural heritage located in the today's Sakha Republic (Yakutia), Russia, play in a process of genesis of ethnic and cultural identity of Yakuts (endonym "Ssakhalar"), one of indigenous people from Turkic linguistic family settled in the region. The authors consider theoretical basis of mechanism for conversion of axiological and sense component of monuments of nature and the major objects of cultural landscape of an area into a resource for elaboration cultural and identification strategies of a region.

Key words: a people's ethnic and cultural identification, strategies of identification, a Russian region, mass consciousness, cultural and natural heritage, cultural identity, cultural values, day-to-day culture, traditional culture, ethnic and cultural consciousness, practices in social and cultural sphere, all-Russian projects, Yakuts, Sakha Republic (Yakutia).
\end{abstract}

УДК 069.014:281.96(571.14-25)

DOI: $10.32340 / 2414-9101-2019-3-14-19$

Е. А. Полякова, доктор исторических наук, доцент Алтайский государственный институт культуры, Барнаульский юридический институт Министерства внутренних дел Российской Федерации (Барнаул, Россия) elena2873@mail.ru

\section{МУЗЕИ СТАРООБРЯДЧЕСКОЙ КУЛЬТУРЫ КАК ИНСТРУМЕНТ ОБЕСПЕЧЕНИЯ НАЦИОНАЛЬНОЙ БЕЗОПАСНОСТИ РОССИИ (НА ПРИМЕРЕ МУЗЕЯ ИСТОРИИ СТАРООБРЯДЧЕСТВА СИБИРИ)}

Аннотация. Стратегия обеспечения национальной безопасности Российской Федерации в сфере культуры ориентирована на преодоление нравственного и культурного кризиса в государстве посредством возрождения традиционных духовно-нравственных ценностей. Механизм формирования национальной идентичности личности современного россиянина средствами традиционной культуры нашёл своё отражение в тексте «Основ государственной культурной политики» (2014 г.) России. Работа российских музеев как институтов социальной памяти составляет основу культурно-охранительной, культурно-просветительной и культурно-воспитательной деятельности в стране. Автор отмечает, что современная отечественная музейная сеть активно пополняется музеями старообрядческой культуры, ведущими работу по сохранению и актуализации исконных русских традиций и позиционирующих старообрядчество как духовное движение.

Ключевые слова: начиональная безопасность в сфере культуры, основы государственной культурной политики, традиционные ценности, старообрядчество, музей.

Второе десятилетие XXI века стало переломным этапом развития культурной политики России. Национальные приоритеты становятся базисом стратегии дальнейшего развития государства. Подтверждением начала обозначенных процессов является и «мюнхенскую речь» В. В. Путина 
(2007), обозначившая национальные интересы России и программный документ «Стратегия национальной безопасности Российской Федерации до 2020 года» (2009) в котором, «впервые массовая, коммерческая, вестернизированная культура, ориентированная на «духовные потребности маргинальных слоев» населения, признавалась угрозой национальной безопасности России» [1, c. 20]. В «Стратегии...» впервые было обозначено, что «решение задач обеспечения национальной безопасности в сфере культуры в среднесрочной и долгосрочной перспективе достигается за счет признания первостепенной роли культуры для возрождения и сохранения культурнонравственных ценностей, укрепления духовного единства многонационального народа Российской Федерации и международного имиджа России в качестве страны с богатейшей традиционной и динамично развивающейся современной культурой» [1, с. 20].

Приоритет традиционной культуры, как базиса культурной политики и духовнонравственного воспитания общества и «главного инструмента передачи и воспроизводства традиционных нравственных ценностей и источник гражданской идентичности» был закреплён в «Основах государственной культурной политики» (2014): «Содержанием современной государственной культурной политики России является создание и развитие системы воспитания и просвещения граждан на основе традиционных для России нравственных ценностей, гражданской ответственности и патриотизма посредством освоения исторического и культурного наследия России» [2].

Особое внимание в обозначенном программном документе уделено музеям. Так, одной из важных задач государственной культурной политики является их «развитие, поддержка и обеспечение», поскольку музеи как институты социальной памяти и образовательная форма культуры «составляют основу культурной деятельности в России, именно они являются основой и обязательным условием соединения культурных ценностей с обществом» и выполняют «важнейшую государственную и общественную функцию исторического и культурного просвещения и воспитания общества» [2].

Обозначенная стратегическая роль музеев в обеспечении национальной безопасности выразилась в расширении музейного мира за счёт музеев, посвящённых сохранению и актуализации исконных русских традиций, ценностей, материального и нематериального наследия - музеев старообрядческой культуры. На современном этапе в Сибири действуют пять ${ }^{*}$ музеев, одним из которых является Музей истории старообрядчества Сибири в г. Новосибирске.

Музей был основан на базе кафедрального соборе Рождества Пресвятой Богородицы силами Новосибирской старообрядческой общины. Инициатором его создания выступил Емельянов Александр Николаевич, которому «понравился музей старообрядчества в Тарбагатае, где местный батюшка собрал большой полевой материал и основал этнографический музей при епархии» [3].

Администрация области и Министерство региональной политики Новосибирской области в рамках реализации «Основ государственной культурной политики» оказали создаваемому музею содействие и выделили в рамках гранта материальные средства «на ремонт помещения и на покупку оборудования, на формирование экспозиции, монтаж света» [4].

30 октября 2016 г. Преосвященный Силуян, епископ Новосибирский и всея Сибири «в присутствии прихожан общины, представителей мэрии, администрации области» торжественно открыл музей, размещённый в цокольном этаже храма. В ходе торжественной церемонии присутствовавшим было показано напутственное видео-обращение предстоятеля Русской Православной Старообрядческой Церкви митрополита Корнилия [4].

\footnotetext{
* Музей Уймонской долины (старообрядчества) (с. Верх-Уймон, республика Алтай); Музей истории и культуры старообрядцев (с. Тарбагатай, республика Бурятия), Церковный музей древлеправославия при храме Рождества Христова Сибирской епархии Русской Древлеправославной Церкви (г. Улан-Удэ, республика Бурятия); Музей истории старообрядчества Сибири (г. Новосибирск, Новосибирская область, основан); Музей-усадьба старообрядческой культуры «Причумышье» (с. Залесово, Алтайский край)
} 
Миссия новосибирского музея укладывается как в «Основы государственной культурной политики», так и в программный документ «Стратегия национальной безопасности Российской Федерации до 2020 года». Она заключается в актуализации в современном социуме древнерусской культуры и традиции, и интеграции наследия культурного мира старообрядчества в современное социокультурное пространство. Создатель музея Александр Емельянов отмечает, что «для многих старообрядчество до сих пор является чем-то сокровенным и непознанным, хотя со времён церковного раскола XVII века судьбы многих поколений русских старообрядцев и история освоения Сибири стали практически неразрывными. Строго сохраняя устои и каноны древлего благочестия, старообрядцы сохранили вместе с тем и свою уникальную бытовую и духовную культуру, а некоторые виды староверческого творчества внесены в список нематериального культурного наследия ЮНЕСКО» [5]. В связи с этим миссия музея заключается в позиционировании старообрядчества как открытого духовного движения. «Несмотря на то, что с 1988 года тема православия широко обсуждается в обществе до сих пор много стереотипов о старообрядчестве. Их путают с неоязычниками. Не каждый придёт в храм и не каждый спросит у священника. Чтобы спросить, надо себя пересилить, а это трудный барьер... Музей же дает информацию разными способами: визуально, вербально. На открытии выставок всегда есть подготовленная аудитория. Они в «теме», они знают, куда и зачем идут. Но есть и люди «с улицы», которые вообще ничего не знали о старообрядцах. Задача музея - не катехизировать, а посеять зерна знания, веры, благочестия. Сохранить историю, чтобы люди задумывались» [3].

Базисом детальности каждого музея являются его фонды. Так, в конце 2018 г. состав передвижного (выставочного) фонда насчитывал около 160 ед. хр. и порядка 50 ед.хр., вставленных в экспозиции. Раритетами музея являются серебряное кадило XIX века, выполненное в форме храма (использовалось только на Пасху) (рис. 1), облачения, архиерейская митра дораскольной формы середины XIX века из собрания Рогожской слободы, выполненная в виде шапки с овчинной натуральной опушкой и декорированная литыми иконами со славянской вязью (рис. 2), самая первая пластинка старообрядческого Морозовского хора 1901 г., дореволюционный колокол 1916 года, отлитый в ярославских мастерских Оловянишникова И. П., поставщика Двора Его Императорского Величества.

Основу фондового собрания музея составляют коллекции иконописи; церковного литья (складни (деисусные, праздничные, богородичные), иконы с просечным литьем и эмалями, нательные кресты XVIII-XIX вв.); церковной утвари (дискосы, потиры и пр.); певческих, богослужебных, поучительных старопечатных книг и рукописей, гектографических изданий начала XX в.; этнографии. В составе фондов музея присутствуют две персональные коллекции старообрядки-отшельницы Агафьи Карповны Лыковой и барнаульского священника тайного рукоположения ${ }^{\dagger}$ отца Романа Павлова.

Способ комплектования фондов являются традиционным для церковных музеев - дарение. Так, основу фондового собрания составляют личные коллекции владыки Силуяна, личные коллекции основателя (А. Н. Емельянова), вещи, принадлежащие общине, принятые в дар от прихожан. Часть музейных предметов предоставлена во временное пользование. Фондовое собрание находится на учёте храма, а не музея.

Трансляция историко-культурного наследия определяется не только составом музейного собрания, но и качеством музейной коммуникации, её идейной составляющей. Так, ключевой идей научной концепции новосибирского музея является показ роли старообрядцев в развитии экономики и культуры Сибири. История старообрядческих общин региона транслируется в контексте ключевых событий российской истории (Великий раскол; освоение Сибири; буржуазнодемократические реформы XIX в.; революция и постреволюционные события; подписание императором Николаем II Указа «Об укреплении начал веротерпимости» в 1905 г.; принятие законов «О свободе совести и религиозных организациях» и «О свободе вероисповеданий»

\footnotetext{
* Находится на колокольне собора.

${ }^{\dagger}$ Без согласования с властью.
} 
в 1990 г.) и деятельности выдающихся исторических личностей, сыгравших особую роль в сохранении и развитии этой религиозной культуры.

Музейная экспозиция отражает историю и современное состояние старообрядчества Сибири посредством трансляции письменных и фотоисточников. История старообрядчества отражена в тематических комплексах, посвящённых протопопу Аввакуму и путям его сибирских ссылок в 1660-х гг., и, помимо информативной составляющей (планшеты), содержит редакции его жития, послания «сибирской братии», репринты, факсимиле и диск с записью фильма «Раскол»с автографом режиссера Николая Досталя [6].

Исторические сведения представлены и в комплексе, посвящённом Новониколаевской старообрядческой общине, и содержат документы, подтверждающие её регистрацию в 1907 г. и территориальное распространение деятельности общины, список её членов и священников, а также сведения из государственных и личных архивов, воспоминания и пр. Отдельное внимание уделено Тарасу Антоновичу Чернышёву, активному деятелю новониколаевской и барнаульской общин (XIX в.). Он был гласным Городской Думы, заместителем председателя Биржевого комитета и распорядителем торгового дома «Чернышёв и сыновья», помогал выпускать журнал «Сибирский старообрядец» и его стараниями община получила право на регистрацию [6].

Продолжает историческую тему комплекс, посвящённый Новониколаевску и купцам Морозовым. Достоверных сведений о связях старообрядцев Новониколаевска с Арсением Ивановичем Морозовым нет, но, как считают сами представители общины «старообрядецпромышленник такого высокого уровня открывать свое дело в далёком краю будет с кем-то из своих единоверцев» [3].

Отдельный блок посвящён судьбам сибирских старообрядческих архиереев конца XIX века и по 30 гг. XX века [6]. Все они были репрессированы и погибли. На данный момент все они канонизированы решениями Священных соборов как исповедники и священномученики [3].

Аттрактивность и ассоциативность экспозициям музея придают вещественные источники, наглядно подтверждающие те или иные явления, события, факты. Одним из наиболее экспрессивных является тематический комплекс «Церковная одежда», в котором представлены облачения: священническое парчовое облачение (стихарь, епитрахиль, поручи и филонь); архиерейское (с архиерейской палицей и обилием титлов); иноческое мужское (малая мантия чёрного цвета с красной каймой) и монашеское женское облачение из Верхнего Абакана. Большая часть элементов облачений была подарена Владыкой Силуяном. В экспозициях музея также выставлены и отдельные предметы, такие как пояс священнический с пряжкой и гравировкой; вериги из скитов Тувы, переданные в музей после смерти владельца, брачные венцы XIX века [3].

Отдельный тематический комплекс посвящён старообрядческим крестам ${ }^{*}$ и их изготовлению. Так, наряду с женскими (с обрамлением в виде листка) и мужскими (с прямыми гранями) крестами XIX века выставлены формы для штамповки (на двух половинах больших пластин сделана зеркальная выборка двух сторон креста, куда вставлялась медная или оловянная пластина, затем сжималась прессом или ударом молота и получался крест) и для кустарной отливки в виде щипцов. Отдельного внимания заслуживает крест надмогильный с Галгофой и обилием титлов (такие кресты на Русском Севере ставили на кладбище - либо в плите, либо в столбе вырезалась ниша, в которую и вставлялся крест) [3].

Отдельный тематический комплекс посвящён богослужебным книгам церковным книгам, в котором представлены «Минея общая» (1609), «Минея сентябрьская» (1619 г.), «Толковый Апокалипсис» (скоропись, вторая половина 17 в.), «Апостол» и «Евангелие служебное», принадлежавшие Афанасию, епископу Иркутско-Амурскому и всего Дальнего Востока, «Служебное евангелие» о. Романа Павлова. В экспозиции также представлены и певческие книги, написанные

\footnotetext{
* На старообрядческих крестах отсутствует распятие. Это связано с тем, что в повседневной жизни человек входит в различные места, в том числе и нечистые, в которые внос икон запрещён.
} 
«крюковой» («знаменной»), «топорной» и «двоезнаменной» (одна строка выполнена «крюковым» письмом, а вторая - «топорным») нотациями [6].

Размещение в экспозиционном пространстве церковных музеев предметов этнографии становится традицией, связанной с необходимостью реконструкции бытовой среды. Этнографическое собрание новосибирского музея включает предметы крестьянского быта (сундуки, прялки, утюги, ступы, туеса, корзины, кринки), рукоделья (вышитые рушники и плетёные пояса), а также традиционные костюмы староверов Алтая и Забайкалья и лестовки со вставленными свитками с Исусовой молитвой [6].

Специфику новосибирского музея составляет наличие тематического комплекса, посвященного известной отшельнице - Агафье Карповне Лыковой, в котором представлены биографические данные, фотографии с её заимки, расположенной у слияния рек Абакан и Еренат; её личные вещи, самостоятельно изготовленные (пояс и лестовка из рыбьих позвонков и домотканой ткани). Особый интерес представляют "Словарь языка старообрядки А. К. Лыковой: письменная речь" в 2-х томах и копия её письма президенту В. В. Путину, датированного 2025 годом от Рождества Христова и 7525 годом от сотворения мира (2017 г.) (документы представлены в экспозиции Музея истории старообрядчества Сибири (г. Новосибирск, Россия)).

Популяризация собраний музея осуществляется в рамках информативного (экскурсии, выставочные проекты) и рекреационного (фестивали, праздники) направлений коммуникативной деятельности и нацелена на гражданско-патриотическое воспитание аудитории. Обзорная экскурсия является базовой формой работы с посетителями, но ограниченность экспозиционного пространства, обуславливает необходимость реализации внемузейной и межмузейной проектной деятельности.

Первые выставочные проекты музея, такие как «Сибирская книжница» реализовывались совместно с Государственной публичной научно-технической библиотекой Сибирского отделения Российской академии наук и проводились на базе библиотеки. Там же проходили фотовыставки Александра Холмогорова «Алтай - природа староверов».

Выставки на базе других музеев практикуются с 2017 г. Постоянными партнерами старообрядческого музея выступают краеведческий и художественный музеи г. Новосибирска, Красноярский художественный музей имени В. И. Сурикова, Минусинский краеведческий музей им. Мартьянова, Коченевский краеведческий музей, Мошковский краеведческий музей. Презентация музейного собрания на других, более доступных площадках традиционно привлекает к себе внимание общественности. А. Н. Емельянов отмечает, что «выставку в Новосибирском краеведческом музее посетило более двух тысяч человек за три недели, а вставку в краеведческом музее села Мошково - более 400 человек течение двух недель» [3].

Крупными межмузейными проектами 2019 года стали выставка "Неизвестное старообрядчество" (Минусинский краеведческий музей им. Мартьянова) и «Выставка православного искусства, посвященная 400-летию города Енисейска» (Красноярский художественный музей имени В. И. Сурикова) [6].

В рамках социально значимой программы «Старообрядчество - пространство культуры» и при поддержке Министерства региональной политики, Музея истории старообрядчества Сибири в Новосибирском художественном музее, состоялась выставка «Завет» московских художников Дмитрия Гусева и Марии Шадчневой [6].

В ходе реализации этой же программы был реализован масштабный проект "Старообрядческий лубок", посвящённый уникальному жанру русской художественной миниатюры. Музеем истории старообрядчества Сибири было выставлено более 40 оригиналов и репродукции XIX века, авторских работ художника Павла Варунина (Эстония) [6].

В сентябре 2019 года на базе музея пройдут выставка "Дары принесенные" и фотовыставка, приуроченная к 20-летию освящения Кафедрального собора во имя Рожества Богородицы г. Новосибирска. В рамках празднования юбилея совместно с домом русских традиций «КрАсота» и при поддержке Министерства региональной политики Новосибирской области запланиро- 
вано проведения рекреационных мероприятий (ярмарка, выступление фольклорных ансамблей, демонстрация народных игр) под общим названием «Праздник для народа». Ранее (2018 г.) вышеуказанными организациями была проведена выставка народного костюма с дефиле и фотосессиями [6].

В целом документирующая и коммуникативная деятельность Музея старообрядческой культуры, осуществляемая в контексте «Основ государственной культурной политики», «Стратегии национальной безопасности Российской Федерации», социально значимых программ, нацелена на демонстрацию вклада старообрядчества в сохранение отечественного духовного и культурного наследия, популяризацию традиционных ценностей и гражданско-патриотических традиций, благотворительности, уважительного отношения к труду, что позволяет считать её инструментом обеспечения национальной безопасности.

\section{Список литературы}

1. Загребин, С. С. Культурная политика в постсоветской России 1991-2015 гг. -Текст "электронный // Вестник Южно-Уральского государственного университета. Сер. Социально-гуманитарные науки. - 2015. T. 15. - № 4. - C. 18-23. - URL: https://cyberleninka.ru/article/n/kulturnaya-politika-v-postsovetskoy-rossii1991-2015-gg_(дата обращения: 28.09.2018).

2. Об утверждении Основ государственной культурной политики : указ Президента Российской Федерации № 808от 24 декабря 2014 г. - Текст : электронный // Консорциум «Кодекс», электронный фонд правовой и нормативно-технической информации : сайт. - URL: http://docs.cntd.ru/document/420242192 (дата обращения: 23.12.2018).

3. Емельянов, А. Н. Интервью с заведующей Музеем истории старообрядчества Сибири (Новосибирск, 7 авг. 2018 г.) ; вела Е. А. Полякова. Личный архив автора. - Текст : непосредственный.

4. Музей истории старообрядчества Сибири открылся в Новосибирске. - Текст : электронный // Алтайский старообрядец : [сайт]. - Барнаул, 2006 - . - URL: https://altaistarover.ru/news/social-life/232-muzejistorii-staroobryadchestva-sibiri-novosibirsk (дата обращения: 28.09.2018).

5. Емельянов, А. Н. В Новосибирске открылся Музей истории старообрядчества Сибири .- Текст : эектронный // Русская вера : [сайт Всемирного Союза староверов]. -2003-. - URL: https://ruvera.ru/news/muzeiy_staroobryadchestva_sibiri (дата обращения: 28.09. 2018).

6. Музей истории старообрядчества Сибири. - Текст : электронный // «Вконтакте» : [социальная сеть]. - URL: https://vk.com/public163639926 (дата обращения: 28.06. 2019).

Elena A. Polyakova, Dr. of Historical Sciences, Associate Professor Altai State Institute of Culture, Barnaul Law Institute of the Ministry of Internal Affairs of the Russian Federation (Barnaul, Russia) elena2873@mail.ru

\section{OLD BELIEVERS' CULTURE MUSEUMS AS A TOOL FOR NATIONAL SECURITY PROTECTION OF RUSSIA (A CASE OF MUSEUM OF HISTORY OF SIBERIAN OLD BELIEF)}

\footnotetext{
Abstract. The strategy of national security protection of the Russian Federation in cultural sphere aimed at overcoming moral and cultural crisis in the state through resurrecting traditional spiritual and moral values. A mechanism of building a personality's patriotic identity by means of traditional culture reflected in the text of "Basic Principles of State Policy of the Russian Federation in Cultural Sphere" (2014). Work of museums, institutions of social memory, lies at the core of conservation and education activities that the country leads in culture sphere. The author notes that the today's Russian museum network widens with museums dedicated to Old Believers' culture; such institutions manage work for conservation and popularization of true Russian traditions and present Old Belief as a spiritual movement.

Key words: national security protection in cultural sphere, Basic Principles of State Policy of the Russian Federation in Cultural Sphere, traditional values, Old Belief, a museum.
} 